Proc. Estonian Acad. Sci. Eng., 2002, 8, 3, 147-161

\title{
Investigation of masonry arches
}

\author{
Réka Macskási \\ Department of Strength of Materials and Structures, Budapest University of Technology and \\ Economics, Müegyetem rkp. 1.-3. K. II. 42, 1521 Budapest, Hungary; \\ macskasi.sil@silver.szt.bme.hu \\ Received 13 September 2001, in revised form 3 April 2002

\begin{abstract}
A method for computing masonry arches consisting of rigid brick voussoires and deformable mortar layers is presented. The brick elements are allowed to move and rotate relative to each other, according to the material model of the mortar. Non-linear constitutive law is applied to eccentric compression and the shear behaviour is determined by both the shear and normal stresses. The applied mathematical method produces the global equilibrium path. The proposed algorithm is appropriate for analysing arches of arbitrary geometry subjected to arbitrary static loads. Some examples which show the influence of the various shape and material parameters are given.
\end{abstract}

Key words: masonry arch, non-linear constitutive law, sliding, equilibrium path, third-order theory.

\section{INTRODUCTION}

For centuries, larger openings were covered by building arches from a large number of small elements. The shape of these structures is determined by the material. Since masonry, layed with or without mortar, does not resist tension, a curved shape evolved which can pass on the loads via compression. No attempt was made to describe the behaviour of masonry arches. Medieval buildings were based on a geometric construction which was suitable in most cases $\left[{ }^{1,2}\right]$.

In the 18th century, when the science of mechanics began to develop $\left[{ }^{3-5}\right]$, many researchers dealt with the mechanical problems of masonry arches $\left[^{6}\right]$. By the beginning of the 19th century, both the experimental and theoretical research of masonry arches was regarded as complete and the interest was transferred to new problems.

In recent years research restarted, with the goal to determine whether the constructions from earlier centuries, mainly masonry arch bridges, meet today's 
requirements. Using the apparatus of modern mechanics, several methods have been developed for the analysis of masonry arches $\left[{ }^{7,8}\right]$.

Some researchers follow and develop the classical theory of masonry arches, which considers the arch as a set of bricks, without tensile strength and with infinite compressive and shear strength in the joints. In this approach, the main problems are the equilibrium and geometry rather than the strength of the material. The main tool of the classical theory is the line of thrust which defines the path followed by the resultant of forces acting in the arch. The statically indeterminate arch contains an infinite number of equilibrium solutions (or thrust line shapes). Considering that the compressive stresses are relatively small compared with the strength of the material, failure occurs only in the case when the line of thrust reaches the outer faces of the arch at four points and the arch becomes a mechanism with hinges at these points. One of the approaches of the classical theory states that if for a given loading at least one state of equilibrium can be found, for which the structure is stable (one line of thrust inside the arch), then it is stable absolutely. As a consequence, a proportional increase of the load never leads to collapse. Another approach, the mechanism method, supposes that the position of the thrust line, i.e. the positions of the hinges at failure, are determined by the given loading. The ultimate value of the load can be calculated from the equilibrium equations. Essentially, the safety of the arch is ensured by its correct shape $\left[{ }^{9,10}\right]$.

These techniques of analysis give no information about the loading stages before failure, stresses, and deformations. Modern formulation of the classical theory contains many enhancements, like finite compressive strength, sliding at joints, etc.

Another, more frequently used technique regards the masonry arch as a homogenous continuum which is divided into (small) finite elements with nonlinear constitutive law. In this approach the size of the elements is introduced artificially. There exists also a more accurate model, requiring large computer capacity, which simulates the bricks and mortar layers separately $\left[{ }^{11}\right]$.

As opposed to the cited homogenous continuum approach and closer to the classical theory, this paper suggests a model for the arch consisting of separated bricks, also called voussoires. In contrast to the finite element models, where the finite element discretization usually follows a rectangular mesh without considering the position of the mortar layers, in the new model the division of the arch corresponds to the physical reality. The material law is applied only to thin mortar layers, the bricks are considered as rigid bodies.

In this model the behaviour of the arch is described more exactly than in the classical theory. Not only the ultimate state can be computed, but detailed results, forces between the voussoires, the actual position of the thrust line as well as stresses and displacements can be found at every loading step. The assumptions and results of the classical theory can be verified with the results of this approach which applies a third-order theory. 
The mathematical model does not apply the variational formulation. It rather solves the underlying ordinary difference equations (supplemented by appropriate boundary conditions) numerically.

\section{THE MECHANICAL MODEL}

The masonry arch is considered as a bar structure consisting of rigid brick voussoires and deformable mortar layers. On the basis of the "length" of the elements, the brick voussoires represent the bars and the mortar layers represent the joints between them. However, in this approach the roles are interchanged because the "short" mortar layers have deformations (similar to the rods of a bar structure) and the "long" bricks do rigid body displacements (similar to the joints of a bar structure). Arbitrary horizontal and vertical loads can be applied at the centre point of every brick element.

The suggested model of the masonry arch is solved by a computer program which uses a multiply recursive algorithm, as illustrated in Fig. 1. The computation has the following three levels.

A. At the joint level, the core of the program describes the behaviour of the mortar layer between two neighbouring bricks. Section 2.1 explains how to obtain the displacements and rotation of a voussoir from the forces and the moment acting on the previous mortar layer.

B. At the second level, the recursion goes through the arch, from the first until the last element. This step is equivalent to the solution of an initial value problem (IVP) associated with a system of ordinary difference equations. Using the forces and moment on the first element as input, the new position of the last element is obtained as output (Section 2.2).

C. At the third level, a simple version of the Parallel Simplex Algorithm (PSA) is used as a mathematical tool to solve the boundary value problem (BVP). The prescribed position of the last element is known, from which the forces and moment on the first element can be found. This mathematical method is outlined in Section 2.3.

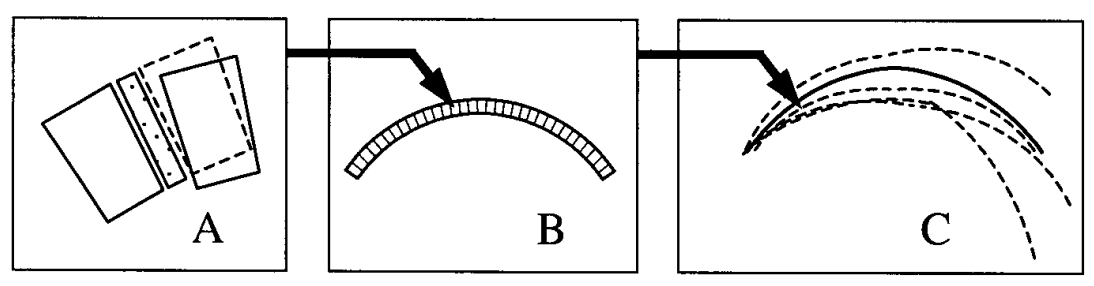

Fig. 1. Recursion levels. 


\subsection{Joint level}

The brick elements can be separated from each other and slide along their contact surface of width $t$, according to the material model of the mortar layer which involves both the axial and shear behaviour of the masonry. (The width of the contact surface is equivalent to the arch thickness if no sliding is present.) The $i$ th mortar layer is subjected to the normal and shear force and bending moment $\left(n_{i}, s_{i}, m_{i}\right)$, from which the relative axial and shear displacements and the relative rotation of the joint $\left(\Delta l_{i}, \Delta t_{i}, \Delta \varphi_{i}\right)$ can be computed as shown in Fig. 2.

The material of the mortar layer is modelled by linear elastic-perfectly plastic axial stress-strain relationship. From the normal force and bending moment the normal stresses and strains and curvature of the cross-section can be obtained. The normal and shear responses are not independent, interaction between them is considered by applying the Coulomb's friction law.

For shear, the constitutive equation is described by a bilinear elastic curve with characteristic value derived from the normal stress diagram, via the friction law. The shear stress and strain are assumed to be uniformly distributed over the cross-section. There is a second connection between normal and shear behaviour, a feedback, with which the shear response influences the normal one. In case of the sliding $(\gamma>0)$, the contact surface between brick elements decreases and the moment value changes, which results in a new normal stress distribution. This feedback is repeated until the shear strain becomes small enough $\left(\gamma<\gamma_{0}\right)$.

The outputs of the calculation are displacements and rotations of the opposite sides of the mortar layer.

\subsection{Arch level}

The second recursion goes from joint to joint along the arch with five steps at every joint. Each of these steps will be described by one compact and one more detailed formula and illustrated by a figure where the capital letters refer to the global and the lower case letters to the local coordinate system, the subscript denotes the serial number of the element and the superscript refers to the components of the masonry (mortar or brick).

Step 1. Determination of the forces and of the moment, acting on the $i$ th mortar layer, in the global coordinate system (Fig. 3):

$$
\begin{gathered}
\mathbf{U}_{i} \cdot \boldsymbol{F}_{i-1}+\mathbf{U}_{i}^{b} \cdot \mathrm{d} \boldsymbol{F}_{i}=\boldsymbol{F}_{i}, \\
{\left[\begin{array}{ccc}
1 & 0 & 0 \\
0 & 1 & 0 \\
Y_{0, i}-Y_{0, i-1} & X_{0, i}-X_{0, i-1} & 1
\end{array}\right] \cdot\left[\begin{array}{c}
H \\
V \\
M
\end{array}\right]_{i-1}+\left[\begin{array}{ccc}
1 & 0 & 0 \\
0 & 1 & 0 \\
\frac{Y_{0, i}-Y_{1, i-1}}{2} & \frac{X_{0, i}-X_{1, i-1}}{2} & 1
\end{array}\right]\left[\begin{array}{c}
\mathrm{d} H \\
\mathrm{~d} V \\
\mathrm{~d} M
\end{array}\right]_{i}=\left[\begin{array}{c}
H \\
V \\
M
\end{array}\right]_{i},}
\end{gathered}
$$




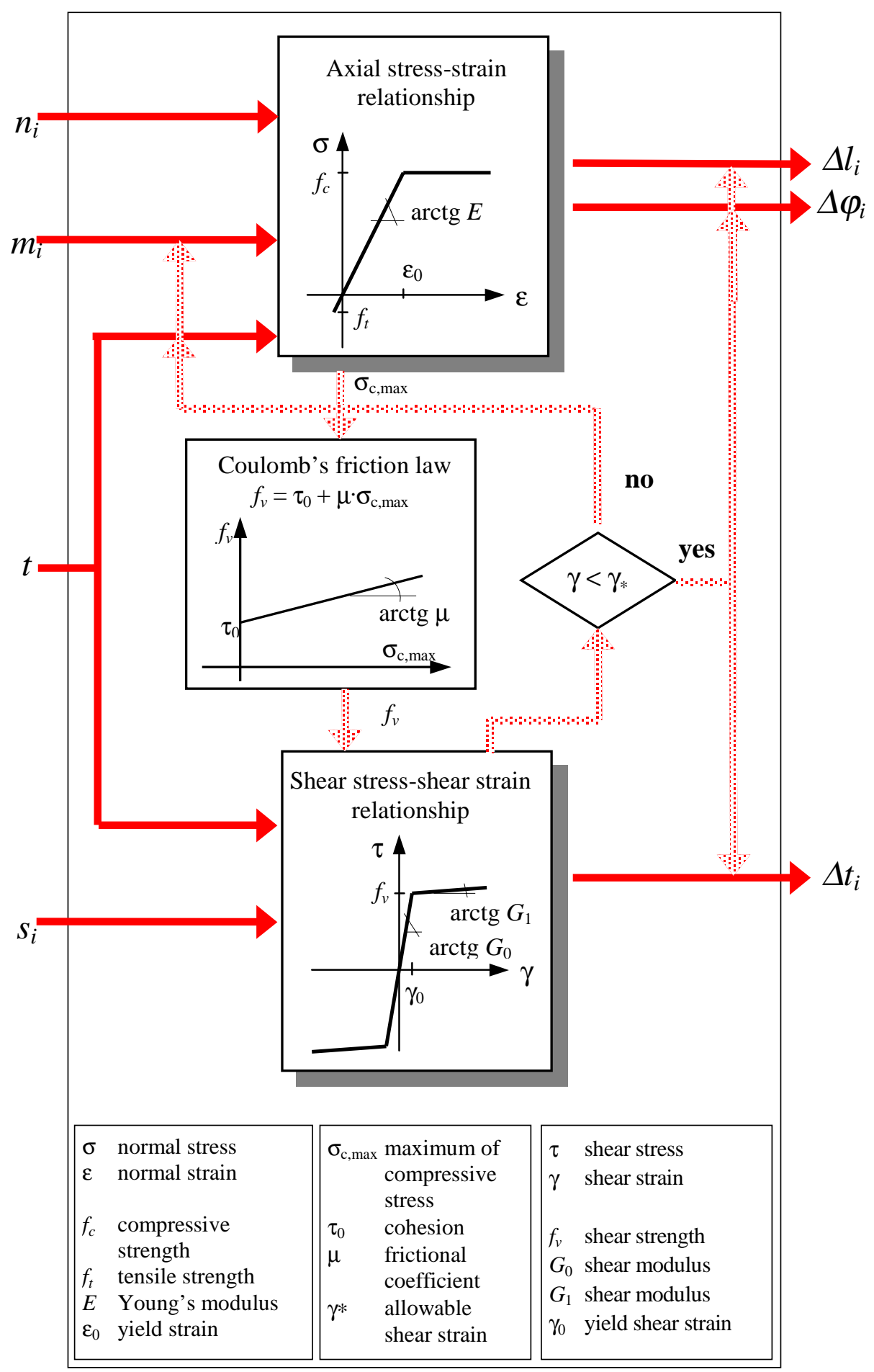

Fig. 2. Material model of the mortar layer. 


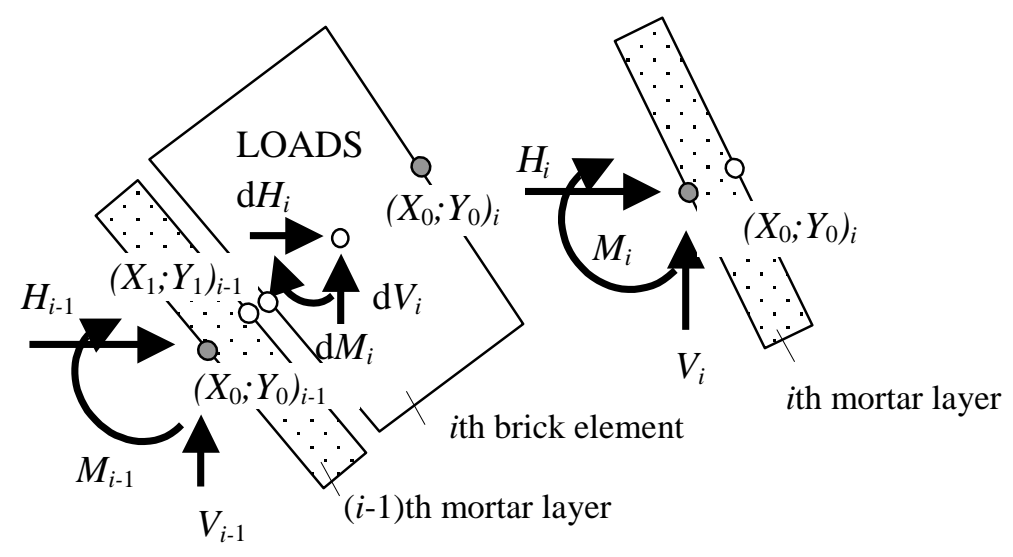

Fig. 3. Illustration of the computational step 1.

where $\boldsymbol{F}_{i}=\left[H_{i}, V_{i}, M_{i}\right]^{*}$ is a vector containing the forces $H_{i}, V_{i}$ and bending moment $M_{i}$, acting on the $i$ th mortar layer, $\mathrm{d} \boldsymbol{F}_{i}=\left[\mathrm{d} H_{i}, \mathrm{~d} V_{i}, \mathrm{~d} M_{i}\right]^{*}$ denotes the vector of loads on the $i$ th brick element, and $\mathbf{U}_{i}$ and $\mathbf{U}_{i}^{b}$ are matrices which describe the equilibrium between the $(i-1)$ th and $i$ th mortar layers and between the $i$ th brick element and $i$ th mortar layer, respectively. In these matrices, $X_{0, i}, Y_{0, i}$ denote the coordinates of the centre point of the surface between the $i$ th brick and the $i$ th mortar element and $X_{1, i-1}, Y_{1, i-1}$ denote the coordinates of the centre point of the surface between the $(i-1)$ th mortar and the $i$ th brick element.

Step 2. Transformation of forces and moment from the global to local coordinate system (Fig. 4):

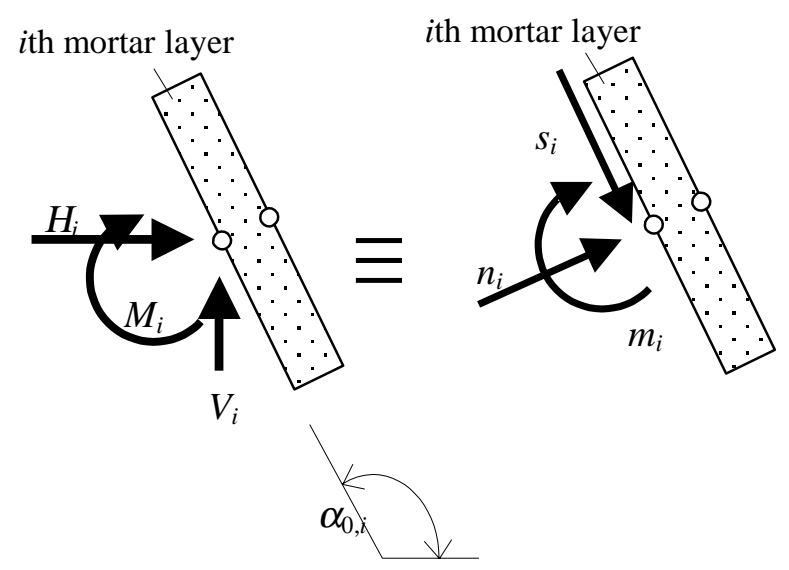

Fig. 4. Illustration of the computational step 2. 


$$
\begin{gathered}
\mathbf{T} \cdot \boldsymbol{F}_{i}=\boldsymbol{f}_{i}, \\
{\left[\begin{array}{ccc}
-\sin \alpha_{0, i} & +\cos \alpha_{0, i} & 0 \\
+\cos \alpha_{0, i} & +\sin \alpha_{0, i} & 0 \\
0 & 0 & 1
\end{array}\right] \cdot\left[\begin{array}{c}
H \\
V \\
M
\end{array}\right]_{i}=\left[\begin{array}{c}
n \\
s \\
m
\end{array}\right]_{i},}
\end{gathered}
$$

where $\boldsymbol{F}_{i}$ and $\boldsymbol{f}_{i}$ are the vectors of forces and the moment as before in global and local coordinate systems, $\mathbf{T}$ is the common rotation matrix, describing the relation between the coordinate systems. The slope of the $i$ th mortar-brick joining surface is denoted by $\alpha_{0, i}$.

Step 3. Computation of the relative displacements and rotation of the $i$ th mortar layer, as described in Section 2.1 and shown in Fig. 2:

$$
f_{i} \Rightarrow d_{i}, \quad\left[\begin{array}{c}
n \\
s \\
m
\end{array}\right]_{i} \Rightarrow\left[\begin{array}{c}
\Delta l \\
\Delta t \\
\Delta \varphi
\end{array}\right]_{i} .
$$

Step 4. Transformation of the displacements and rotation from local to global coordinate system (Fig. 5):

$$
\begin{gathered}
-\mathbf{T} \cdot \boldsymbol{d}_{i}=\boldsymbol{D}_{i}, \\
{\left[\begin{array}{ccr}
+\sin \alpha_{0, i} & -\cos \alpha_{0, i} & 0 \\
-\cos \alpha_{0, i} & -\sin \alpha_{0, i} & 0 \\
0 & 0 & -1
\end{array}\right] \cdot\left[\begin{array}{c}
\Delta l \\
\Delta t \\
\Delta \varphi
\end{array}\right]_{i}=\left[\begin{array}{c}
\Delta X \\
\Delta Y \\
\Delta \vartheta
\end{array}\right]_{i},}
\end{gathered}
$$

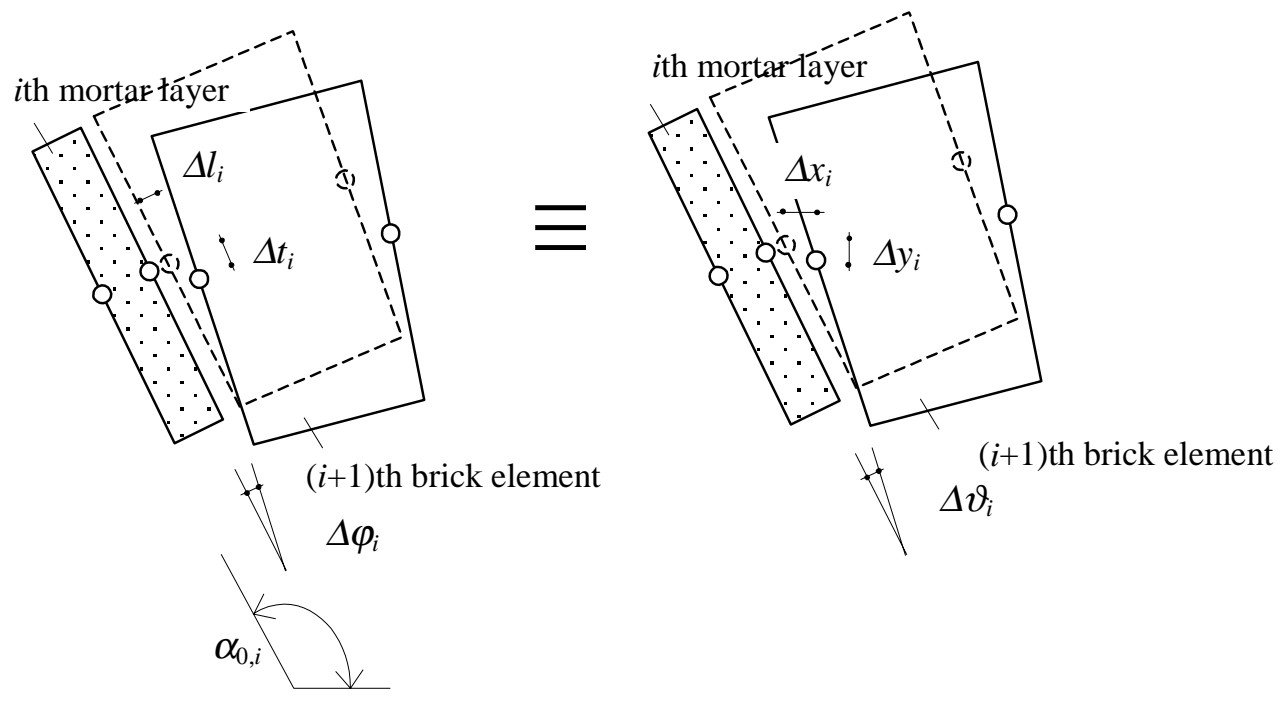

Fig. 5. Illustration of the computational step 4 . 
where $\boldsymbol{d}_{i}=\left[\Delta l_{i}, \Delta t_{i}, \Delta \varphi_{i}\right]^{*}$ and $\boldsymbol{D}_{i}=\left[\Delta X_{i}, \Delta Y_{i}, \Delta \vartheta_{i}\right]^{*}$ are the vectors of displacements and rotation of the surface between the $i$ th mortar and the $(i+1)$ th brick element in the local and global coordinate systems, respectively.

Step 5. Determination of the new position of the $(i+1)$ th mortar layer (Fig. 6):

$$
\begin{gathered}
\boldsymbol{Z}_{0, i}+\boldsymbol{D}_{i}+\boldsymbol{G}_{i}^{m}=\boldsymbol{Z}_{1, i},\left[\begin{array}{c}
X_{0} \\
Y_{0} \\
\alpha_{0}
\end{array}\right]_{i}+\left[\begin{array}{c}
\Delta X \\
\Delta Y \\
\Delta \vartheta
\end{array}\right]_{i}+\left[\begin{array}{c}
l_{i}^{m} \cdot \cos \beta_{i}^{m} \\
l_{i}^{m} \cdot \sin \beta_{i}^{m} \\
0
\end{array}\right]=\left[\begin{array}{c}
X_{1} \\
Y_{1} \\
\alpha_{1}
\end{array}\right]_{i} \\
\boldsymbol{Z}_{1, i}+\boldsymbol{G}_{i+1}^{b}=\boldsymbol{Z}_{0, i+1},\left[\begin{array}{c}
X_{1} \\
Y_{1} \\
\alpha_{1}
\end{array}\right]_{i}+\left[\begin{array}{c}
l_{i+1}^{b} \cdot \cos \left(\beta_{i+1}^{b}+\Delta \vartheta_{i}\right) \\
l_{i+1}^{b} \cdot \sin \left(\beta_{i+1}^{b}+\Delta \vartheta_{i}\right) \\
\gamma_{i+1}^{b}
\end{array}\right]=\left[\begin{array}{c}
X_{0} \\
Y_{0} \\
\alpha_{0}
\end{array}\right]_{i+1}^{b},
\end{gathered}
$$

where $\boldsymbol{Z}_{0, i}=\left[X_{0, i}, Y_{0, i}, \alpha_{0, i}\right]^{*}$ and $\boldsymbol{Z}_{1, i}=\left[X_{1, i}, Y_{1, i}, \alpha_{1, i}\right]^{*}$ denote the coordinates of the centre points and slopes of the surfaces between the $i$ th brick and the $i$ th mortar and the $i$ th mortar and the $-(i+1)$ th brick elements. The arch geometry is given by the vectors $\boldsymbol{G}_{i}^{m}$ and $\boldsymbol{G}_{i+1}^{b}$ which contain the width $l_{i}$, the wedge angle $\gamma_{i}$, and the slope of the $i$ th element $\beta_{i}$.

The above five steps must be repeated $N+1$ times $(N$ denotes the number of the bricks) from the beginning to the end of the arch, in order to obtain the position of the last element.

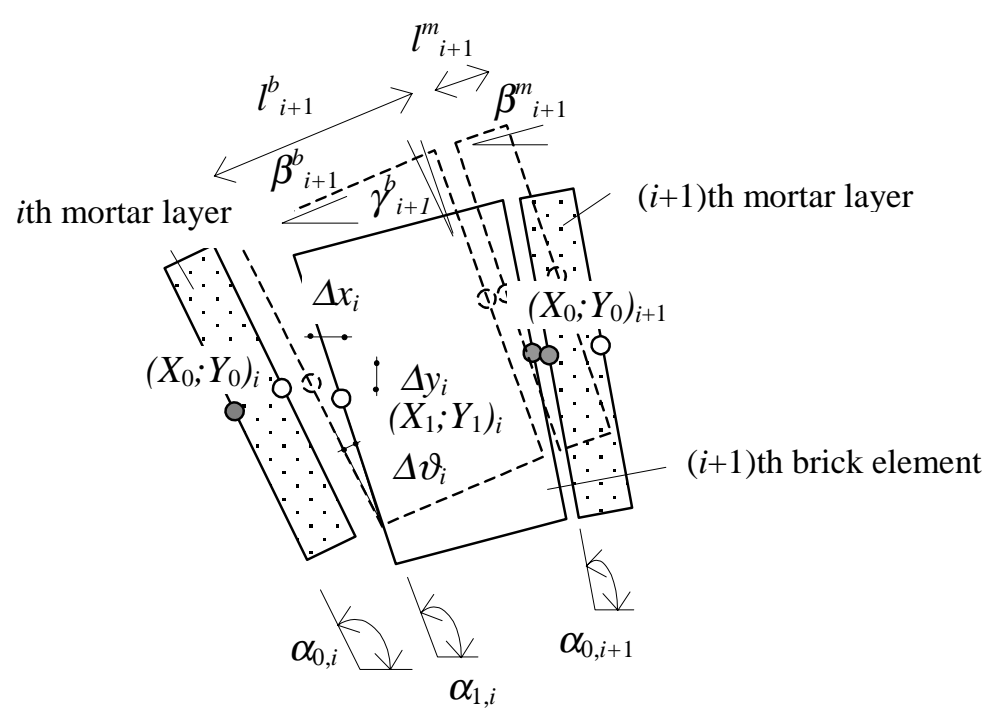

Fig. 6. Illustration of the computational step 5. 


\subsection{Solution of the boundary value problem}

The applied mathematical method is an earlier version of the PSA (not to be confused with the simplex algorithm in linear programming!). PSA has been developed for problems in structural mechanics by Domokos and Gáspár [ $\left.{ }^{12,13}\right]$, based on the so-called Piecewise Linear method of Allgower and Georg $\left[{ }^{14}\right]$.

The basic idea of the method is that calculation of the structure is regarded as a multipoint BVP. The solution of the BVP can be found in the space which is spanned by the non-constant initial conditions and the load parameter. This space is the so-called global representation space of the BVP. Each point in this space represents a parametric configuration of the initial value problem, but only those IVPs satisfy the boundary conditions which are associated with points of the equilibrium path. We divide the $k$-dimensional global representation space into simplices, which are defined by $k+1$ vertices.

The values of the function, belonging to the vertices of the simplex, can be calculated by any IVP solving algorithm. These values can be linearly interpolated inside the simplex. The solution yields a straight line which has two intersection points with the surface of the simplex: the initial point and a second, exit point. Reflecting the simplex to the plane of the exit point, the continuation of the equilibrium path is obtained.

This computation requires an initial point. Namely, at least one equilibrium configuration of the BVP must be known in advance. Usually the trivial, unloaded configuration, the origin of the global representation space is used as the first point.

The advantages of the applied method are that there are restrictions neither on the material law nor on the order of magnitude of deformations. Thus it allows to take into consideration both physical and geometrical non-linearities. In addition, not only the ultimate load, but the overall behaviour of the structure, the equilibrium path, is obtained. The PSA does not involve iteration, it is based on linear interpolation. The method is efficient, because one additional point on the equilibrium path requires solution of only one IVP.

The problem of the masonry arch can be regarded as a BVP whose unknown quantities, the forces and moment on the first element, can be found by satisfying the boundary conditions. In case of our masonry arch, a four-dimensional space is suitable. The parameters of the IVP are $H_{0}, V_{0}, M_{0}$, and the load parameter, $Q$, as illustrated in Fig. 7. The boundary conditions, which must be satisfied at the end point of the arch, prescribe that the position of the last element must coincide with its position in the unloaded case:

$$
\begin{gathered}
X_{1, N}\left(H_{0}, V_{0}, M_{0}\right)-X_{1,0}=0, \\
Y_{1, N}\left(H_{0}, V_{0}, M_{0}\right)-Y_{1,0}=0, \\
\alpha_{1, N}\left(H_{0}, V_{0}, M_{0}\right)-\alpha_{1,0}=0 .
\end{gathered}
$$




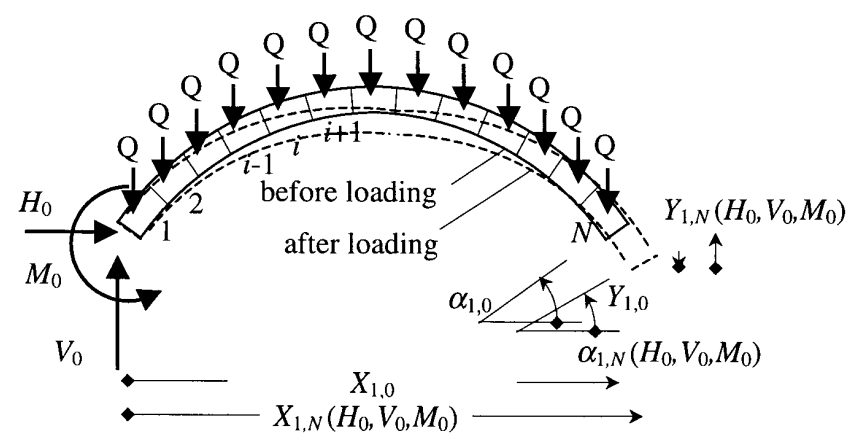

Fig. 7. Parameters and boundary conditions.

\section{EXAMPLES AND RESULTS}

In this section some numerical examples are presented. First, a computation for a common arch was carried out. After that, a parametric study was made to investigate the effect of different geometrical and material factors and a special load factor. The geometrical and mechanical properties of the arch and the load are summarized in Table 1. The circular arch is loaded with self weight, frictional coefficient is 0.5 .

The load-deflection curve begins with a linear part as shown in Fig. 8. Later, with growing applied load it becomes flatter. This change is related to the change of the load-bending moment diagram in Fig. 9. If we approach in one or more joints to the plastic limit, the rotations start to grow rapidly. This causes increasing deflection of the mid-span point.

Figure 9 shows also the line of thrust and the different positions of the opened joints, which correspond to the parts of the load-moment diagram.

In the elastic part of the diagram, cracks appear and grow at the mid-span point and near the supports, at a few bricks above them. As the curve becomes flatter, the cracks start growing and further cracks open at the springings. At maximum load the biggest cracks are at a few bricks above the supports. Beyond the peak of the diagram, the bending moment at the supports is decreasing, what corresponds to the closing of the support cracks and appearance of a big crack at the mid-span point.

Table 1. Geometry and material of the arch

\begin{tabular}{lrllr}
\hline \multicolumn{1}{c|}{ Geometrical parameters, cm } & \multicolumn{2}{c}{ Material parameters, N/mm } \\
\hline Free span & 200 & Compressive strength & 10 \\
Height at mid-span & 54 & Modulus of elasticity & 10000 \\
Thickness & 12 & Tensile strength & 1 \\
Width of the brick & 6.5 & Cohesion & 0.3 \\
Width of the mortar & 1 & &
\end{tabular}




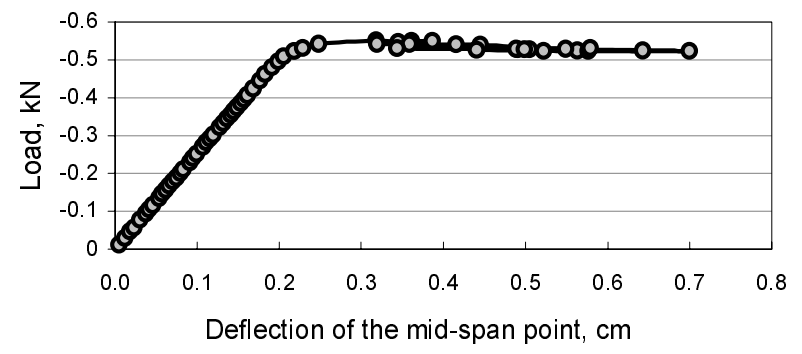

Fig. 8. Load-deflection curve of the arch.

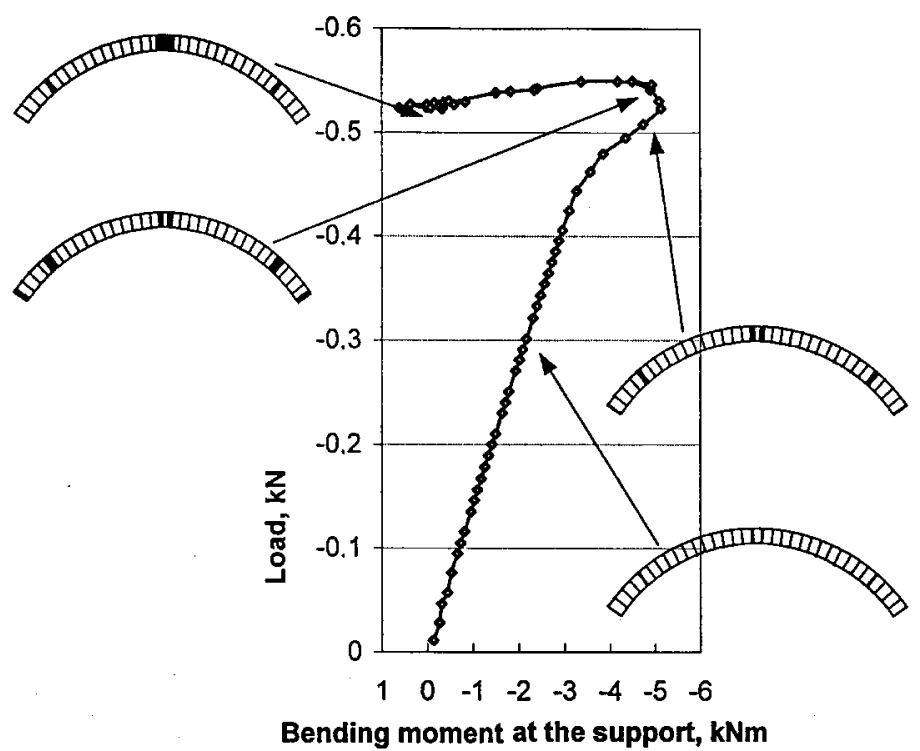

Fig. 9. The variation of the bending moment at the support and the position of the opened joints at different loading levels.

The changing curve of the line of thrust is the result of the loading process. At the ultimate load, the line of thrust approaches the edges of the cross-section and the arch becomes a mechanism that collapses.

In the parametric study, the investigated arch was regarded as a starting point. Only one of the geometrical or material properties was varied, the others remained unchanged.

The geometry is specified by the arch shape, span, thickness, and height. Among the material properties we considered the compressive strength, modulus of elasticity, and cohesion. The presence of fill over springing, as a special load, also influences the load bearing capacity. The results are plotted in Figs. 10 to 15 . 
Figure 10 shows different load bearing capacities of arches of different shapes. The shape of the strongest arch is closest to the line of the thrust for selfweight.

Figures 11 and 12 show the effect of the span and arch thickness on the ultimate load.

Uniting these results in Fig. 13, it becomes evident, that not the absolute dimensions, but the ratio of them is determinant. This refers to the importance of the geometry of the arch.

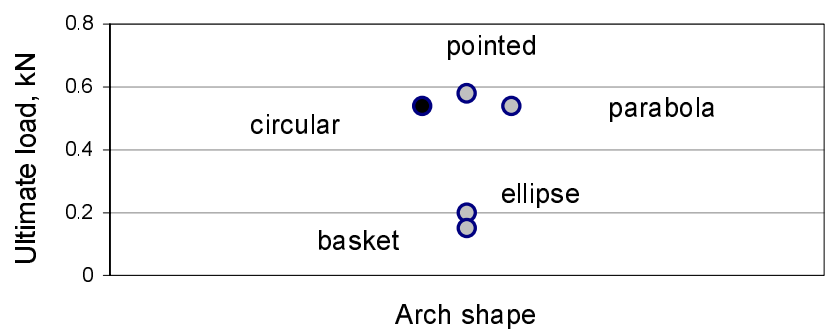

Fig. 10. Effect of arch shape on the load bearing capacity.

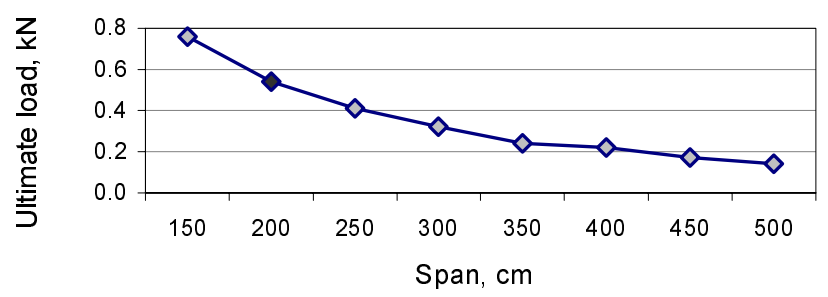

Fig. 11. Effect of the span on the load bearing capacity.

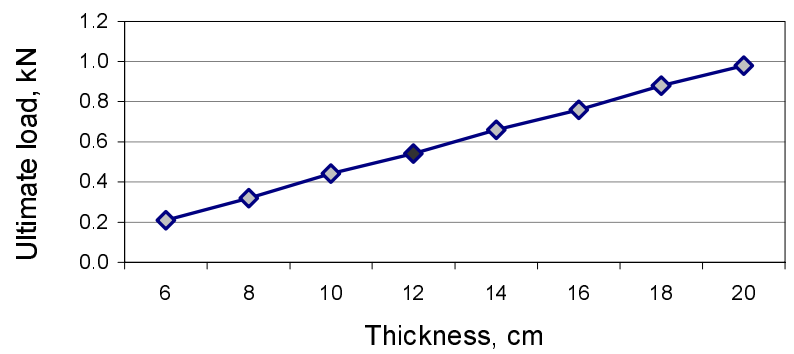

Fig. 12. Effect of the arch thickness on the load bearing capacity. 


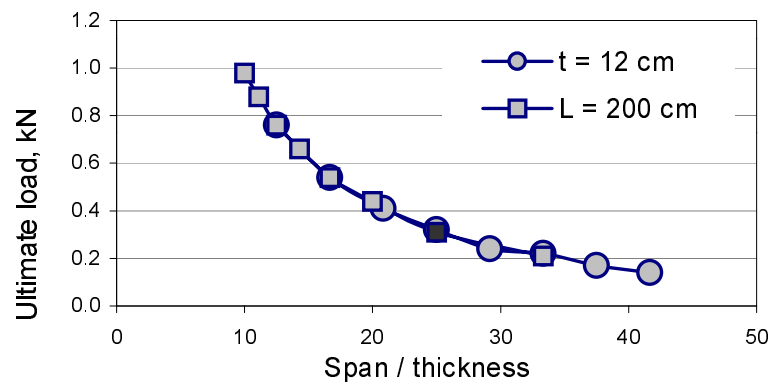

Fig. 13. Effect of the ratio span/thickness on the load bearing capacity.

Arch height has an advantageous effect on the load carrying capacity up to a certain value; after that it declines as illustrated in Fig. 14.

Figure 15 shows that the amount of fill above springing, similar to the arch height, has an optimal value. In spite of the fact that the fill represents an increased weight, it enhances the load bearing capacity, because it keeps the thrust line inside the arch.

Increasing linearly the compressive strength, which is connected with the increase of the modulus of elasticity, causes linear increase in the ultimate load. The variation of cohesion did not affect the load bearing capacity in the examined cases, because sliding did not occur.

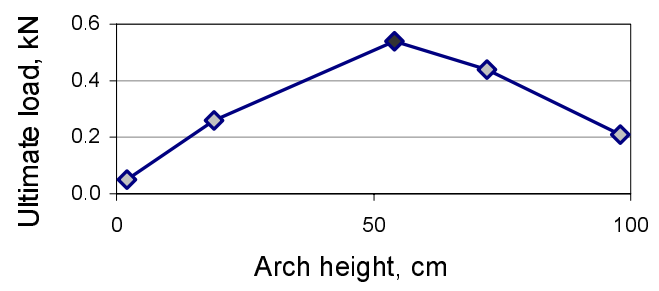

Fig. 14. Effect of the arch height on the load bearing capacity.

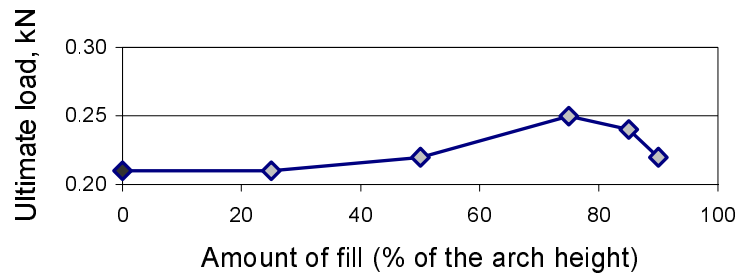

Fig. 15. Effect of the amount of fill on the load bearing capacity. 


\section{CONCLUSIONS}

In this paper a method for the analysis of masonry arches is presented, which can handle both physical and geometrical non-linearities. In contrast to the customary finite element analysis, this algorithm uses a special discretization, according to the size of the elements, and the results can be found by solving a boundary value problem. Information is obtained not only about the ultimate load, but also about the failure mechanism and the forces at any joint. Thirdorder theory was taken into consideration; therefore the rearrangement of critical cross-sections could be observed.

We found that the geometry of the arch is of crucial importance according to the classical theory. The geometrical relation between the thrust line and the position of the cross-section along the arch determines the behaviour of the arch, the failure mode, and the positions of the hinges. Considering finite compressive strength, it was found that the strength and stiffness of the arch have also a significant effect on the collapse load.

\section{ACKNOWLEDGEMENT}

The support of the OTKA grant No. T031744 is gratefully acknowledged.

\section{REFERENCES}

1. Mark, R. Experiments in Gothic Structure. MIT, Cambridge, Massachusetts, London, 1982.

2. Heyman, J. The Stone Skeleton. University Press, Cambridge, 1995.

3. Timoshenko, S. P. History of Strength of Materials. McGraw-Hill, London, 1953.

4. Andai, P. A mérnöki alkotás története. Mủszaki Könyvkiadó, Budapest, 1959.

5. Straub, H. Die Geschichte der Bauingenieurkunst. Birkhauser Verlag, Basel, 1949.

6. Heyman, J. The Masonry Arch. Ellis Horwood, Chicester, 1982.

7. Molins, C. Numerical simulation of the ultimate response of arch bridges. In Structural Analysis of Historical Constructions II. Possibilities of Numerical and Experimental Techniques (Roca, P., González, J. L., Oñate, E., and Lourenço, P. B., eds.). CIMNE, Barcelona, 1998, 93-123.

8. Hughes, T. The testing, analysis and assessment of masonry arch bridges. In Structural Analysis of Historical Constructions. Possibilities of Numerical and Experimental Techniques (Roca, P., González, J. L., Marí, A. R., and Oñate, E., eds.). CIMNE, Barcelona, 1997, 64-85.

9. Heyman, J. Mechanical behaviour of arches and vaults. In Structural Analysis of Historical Constructions II. Possibilities of Numerical and Experimental Techniques (Roca, P., González, J. L., Oñate, E., and Lourenço, P. B., eds.). CIMNE, Barcelona, 1998, 1-6.

10. Hendry, A. W. Structural Masonry. MacMillan, London, 1990.

11. Lourenço, P. B. Computational Strategies for Masonry Structures. Delft Univ. Pr., Delft, 1996.

12. Domokos, G. and Gáspár, Zs. A global, direct algorithm for path-following and active static control of elastic bar structures. Mech. Struct. Mach., 1995, 23, 549-571.

13. Szeberényi, I. and Domokos, G. Solving generalized boundary value problems with distributed computing and recursive programming. In Lecture Notes in Computer Science. No. 1697 (Dongarra, J. et al., eds.). Springer, Berlin, 1999, 267-274.

14. Allgower, E. L. and Georg, K. Numerical Continuation Methods: An Introduction. Springer, Berlin, 1990. 


\section{Müüritisvõlvide uurimine}

\section{Réka Macskási}

On kirjeldatud müüritisvõlvide arvutamise meetodit, mis vaatleb võlvi jäikadest võlvikividest ning deformeeruvatest mördikihtidest koosnevana. Kivid võivad üksteise suhtes pöörduda ja nihkuda vastavuses mördi deformeeruvuse mudeliga. Ekstsentrilist survet on kirjeldatud mittelineaarse olekuvõrrandiga ning nihkedeformatsioone vaadeldud sõltuvana nihke- ja normaalpingetest. Meetod lubab määrata võlvi survetrajektoori ning sobib meelevaldse kuju ja koormusega võlvide arvutamiseks. On toodud mitmeid näiteid, mis iseloomustavad võlvi geomeetria ja materjali omaduste mõju võlvi deformeerumisele. 